\title{
Ecological and hygienic assessment of environment in the town with glass packaging production
}

\author{
Anton Martsev $^{1 *}$, and Oleg Selivanov ${ }^{1}$ \\ ${ }^{1}$ Vladimir State University named after A.G. and N.G. Stoletovs', 600000, 87, Gor'kogo st., Vladimir, \\ Russia
}

\begin{abstract}
The population of the industrialized centers is constantly affected by the complex of technogenic factors of environmental pollution. The leading technogenic factor is known to impact negatively the population health is air pollution. Technogenic air pollution in cities is caused by the emissions of contaminants both as a result of motor transportation and industrial enterprises. This impact is one of the main reasons for the public health deterioration. Glass production is among such sources. Air pollution with toxic substances causes soil pollution, which ecological and sanitary condition can serve as a marker of environmental pollution rate. The study objective was the ecological and hygienic environment assessment of the Gorokhovets town in the Vladimir region, where modern glass empties production is functioning. Statistics of the regional official services in Gorokhovets district of the Vladimir region, as well as data from our own research have been applied for the research. Heavy metals in soil have been detected by x-ray fluorescence method applying spectrometer "Spectroscan MAX-G". Anions content in soils was determined using water extracts from soil samples by capillary electrophoresis applying device "Kapel-104". Results. The statistics published by the official regional state services on the gross amount of air pollutants emissions have been analyzed. Data on the heavy metals (HM) and anions content in various parts of Gorokhovets have been obtained. Conclusion. The ecologic-hygienic assessment of environment allowed to reveal that vehicles make the largest contribution to the air pollution in Gorohovets area in recent years. The main stationary air pollution source $n$ is the glass works "Rusdzham" as first of all nitrogen oxides are its byproducts.
\end{abstract}

\section{Introduction}

The population of industrialized centers constantly faces technogenic factors complex of environmental pollution - one of the key reasons for health deterioration. Air pollution - the leading technogenic factor - is known to affect population health negatively. $[1,2,3,4,5]$. Technogenic pollution of urban air is caused by contaminants emissions caused by motor

\footnotetext{
${ }^{*}$ Corresponding author: martsevaa@yandex.ru
} 
transport and industrial enterprises [6]. Glass production is one of such sources. The harmful pollutants are formed as a result of glass producing from the charge at high temperatures, and many of its components possess volatility within the glass formation temperature range. To reach the necessary temperature, it is required to burn a large amount of organic fuel, which inevitably leads to air pollution with toxic contaminants, primarily with oxides of nitrogen, carbon, sulfur. The increased concentrations of these substances in the surface layer of the atmosphere can impact environment negatively. Atmospheric pollution with toxic substances causes soil pollution, which ecological and hygienic condition can serve as a marker of environmental pollution rate [7].

The research objective was ecological and hygienic assessment of the environment in Gorokhovets town, Vladimir region, where modern glass packaging production is located.

\section{Materials and methods}

Statistics of the regional official services, as well as data obtained in the study have been used for the research. Data on stationary sources and motor transport emissions into the air (2001-2015) in Gorohovets area were received from the regional administration reports "About the state of environment and public health of Vladimir region" for 2001-2015; the qualitative composition of emissions from a glass plant from the thesis N.A. Ishunkina [8]. The soil sampling in Gorokhovets at various reference sites, as well as their analysis regarding the content of anions and heavy metals, was carried out personally in the summer of 2018. The samples were prepared for analysis in compliance with State Standard GOST 14.02-84. Heavy metals detection in soil was carried out by X-ray fluorescence method applying spectrometer "Spectroscan MAX-G" in compliance with Environmental State Standards PND F 16.1.42-04. Anions content in soil was determined using water extracts from soil samples applying capillary electrophoresis device "Kapel-104". To quantify gas and dust emissions impact on population, Y.E. Saet and co-authors proposed to apply emission load coefficient [9], which was calculated by dividing pollutants emissions into the atmosphere from stationary sources per 1 person living in this area. "STATISTICA" software was used to process the data.

\section{Results}

Gorokhovets district is an administrative-territorial unit and a municipal district of the Vladimir region, located in the East of the region bordering the Nizhny Novgorod region The total population of the district in 2017 was 21,416 people [10]. The district is crossed by the Federal high way M-7, which is characterized by continuous heavy traffic of vehicles.

According to the official statistics, published by the Vladimir region administration, the main source of air pollution in Gorokhovets district, as well as in the whole region, in recent years is motor transport. In 2015 it amounted 65.8\% (table 1). It primarily depends on the increase of production capacity of the region. The main stationary source of air basin pollution in the district for the last two decades was the enterprise "Ruscam ltd.", one of the largest factories in Europe producing glass packaging.

The town of Gorokhovets is an administrative and industrial center of the district, and home to about $60 \%$ of the district population (in 2017 about 12948 persons) [10]. However, right here the main stationary source of air pollution in the area is located. It is glass packaging producing plant "Ruscam", which started its activities in 2002. The emissions amount into the atmosphere from stationary sources in this area increased from 0.7 thousand tons in 2001 up to 0.95 thousand tons in 2015, reaching its maximum in 2005 
(3.83 thousand tons). When calculating the emission load coefficient according to Saet, it appeared that one city resident accounts for about 80 tons of enterprise emissions per year (on average from the calculations in 2006-2013).

Table 1. Data of emissions into the air in Gorohovets area, thousand tons

\begin{tabular}{|c|c|c|c|c|c|c|c|c|c|c|}
\hline year & 2006 & 2007 & 2008 & 2009 & 2010 & 2011 & 2012 & 2013 & 2014 & 2015 \\
\hline $\begin{array}{c}\text { motor } \\
\text { transport }\end{array}$ & 0,86 & 0,85 & 0,88 & 0,89 & 1,42 & 2,10 & 2,00 & 1,80 & 1,80 & 1,83 \\
\hline $\begin{array}{c}\text { stationary } \\
\text { sources }\end{array}$ & 3,24 & 2,02 & 1,59 & 2,24 & 2,28 & 2,02 & 1,78 & 1,26 & 1,08 & 0,95 \\
\hline "Ruscam ltd." & 2,59 & 1,32 & 0,93 & 1,76 & 1,76 & 1,65 & 1,47 & 1,00 & - & - \\
\hline total & 4,10 & 2,87 & 1,81 & 2,65 & 3,70 & 4,12 & 3,78 & 3,06 & 2,88 & 2,78 \\
\hline
\end{tabular}

Heavy metals and anions content was analyzed in the city soil in order to detect possible increased concentrations associated with the air basin pollution. Sampling points were selected in accordance with the proximity to possible pollution sources and their maximum impact on population (plant "Ruscam" perimeter and city center). A control soil sample was taken outside the city, in the Klyazma river floodplain (Figure 1). The research results are presented in Tables 2, 3 .

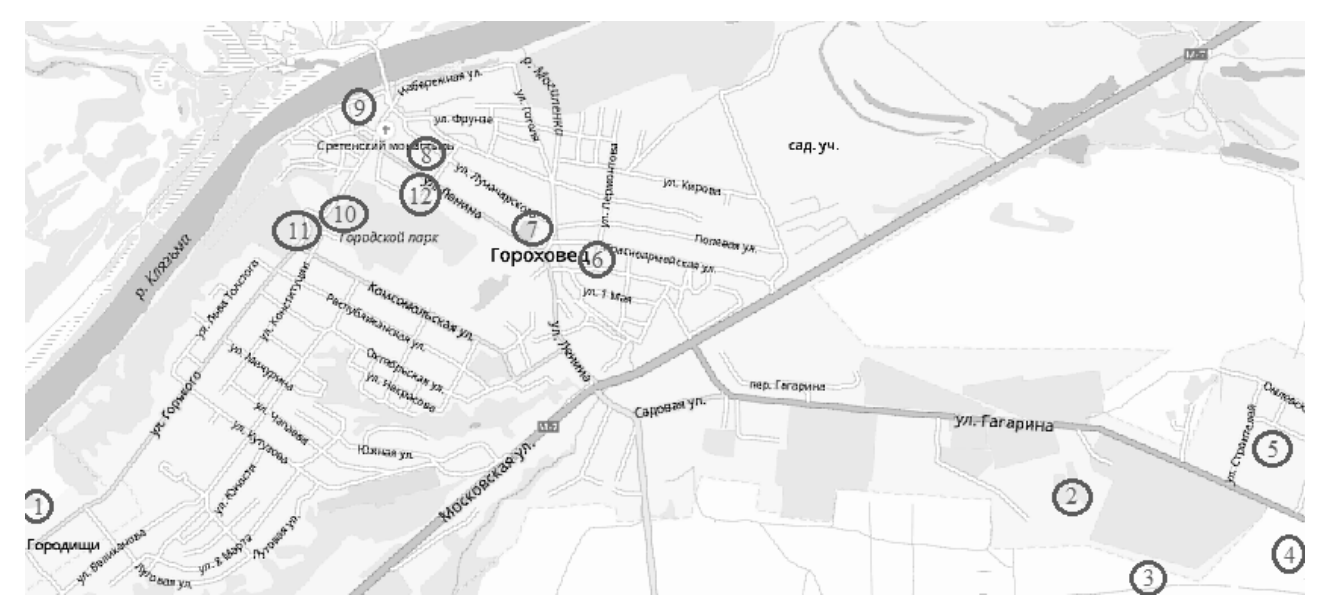

Fig. 1. Soil Sampling Points

Heavy metals and anions accumulation mechanism in soil is associated with the atmospheric pollution of the city air basin by the vehicles exhaust gases and the activity of the existing large industrial enterprises and, in particular, the glass packaging plant "Ruscam". Melting glass (colorless, green, brown) in glass furnaces in glass-packaging industries is known to release aluminum oxide (III), iron oxide (III), cobalt and cerium oxides (which are a part of the coloring pigments) into the atmosphere [11]. The following heavy metals: $\mathrm{Pb}, \mathrm{Zn}, \mathrm{Cu}, \mathrm{Ni}, \mathrm{Cr}, \mathrm{V}, \mathrm{Co}$ can get into air with the vehicles exhaust gases. 
Table 2. Anions content in Gorokhovets soil, $\mathrm{mg} / \mathrm{l}$

\begin{tabular}{|c|c|c|c|c|c|c|}
\hline $\begin{array}{l}\text { Soil anions } \\
\text { sampling } \\
\text { points }\end{array}$ & $\mathrm{Cl}^{-}$ & $\mathrm{SO}_{4}{ }^{2-}$ & $\mathrm{C}_{2} \mathrm{O}_{4}{ }^{2-}$ & $\mathrm{NO}_{3}{ }^{-}$ & $\mathrm{PO}_{4}{ }^{2-}$ & $\mathrm{CH}_{3} \mathrm{COO}^{-}$ \\
\hline 1 & $10,6 \pm 1,25$ & $3,1 \pm 0,22$ & $2,8 \pm 0,10$ & $1 \pm 0,08$ & $0,4 \pm 0,02$ & $8,6 \pm 0,65$ \\
\hline 2 & $7,4 \pm 0,33$ & $2,5 \pm 0,21$ & $2,3 \pm 0,07$ & $3,2 \pm 0,82$ & $0,2 \pm 0,07$ & $4,2 \pm 1,32$ \\
\hline 3 & $7,2 \pm 0,60$ & $7,0 \pm 3,94$ & $1,5 \pm 0,07$ & $3,7 \pm 0,45$ & $0,35 \pm 0,35$ & $2,7 \pm 1,81$ \\
\hline 4 & $12,5 \pm 6,51$ & $5,6 \pm 0,52$ & $4,1 \pm 1,24$ & $9,8 \pm 2,83$ & $0,2 \pm 0,07$ & $3,5 \pm 0,42$ \\
\hline 5 & $7,7 \pm 4,52$ & $3,7 \pm 2,73$ & $1,6 \pm 0,11$ & $2,8 \pm 1,14$ & $0,6 \pm 0,52$ & $4,3 \pm 0,24$ \\
\hline 6 & $7 \pm 0,84$ & $3,4 \pm 0,15$ & $2,2 \pm 0,32$ & $8,9 \pm 0,67$ & $0,2 \pm 0,01$ & $5,4 \pm 0,48$ \\
\hline 7 & $5,9 \pm 0,45$ & $3,7 \pm 0,71$ & $1,7 \pm 0,2$ & $4,2 \pm 0,94$ & $0,1 \pm 0,01$ & $2,9 \pm 0,8$ \\
\hline 8 & $6,5 \pm 0,32$ & $2,7 \pm 0,21$ & $1,8 \pm 0,14$ & $6,1 \pm 0,45$ & $0,5 \pm 0,02$ & $8 \pm 0,56$ \\
\hline 9 & $4,4 \pm 0,31$ & $7,1 \pm 0,43$ & $2,1 \pm 0,16$ & $4,8 \pm 0,38$ & $0,1 \pm 0,01$ & $3,9 \pm 0,27$ \\
\hline 10 & $4,2 \pm 0,24$ & $4,1 \pm 0,29$ & $2,5 \pm 0,19$ & $5,6 \pm 0,47$ & $0,7 \pm 0,45$ & $3,1 \pm 0,27$ \\
\hline 11 & $4,5 \pm 0,25$ & $4,6 \pm 0,33$ & $1,7 \pm 0,10$ & $4,8 \pm 0,39$ & $0,9 \pm 0,67$ & $3,3 \pm 0,23$ \\
\hline 12 & $6,2 \pm 0,54$ & $3,5 \pm 0,31$ & $3,3 \pm 0,28$ & $7,0 \pm 0,62$ & $0,6 \pm 0,54$ & $3,9 \pm 0,37$ \\
\hline
\end{tabular}

The analysis of the city soil samples showed that the increased content of lead (sampling points No. 6,8,9) and zinc (sampling points No. 7,11,12) was detected. It might depend on heavy traffic highways and diesel and gasoline vehicles traffic in the city center. The sampling points along the glass packaging plant "Ruscam" perimeter revealed the excess HM concentrations in soil, compared to the control samples.

Glass packaging production is known to require high heat expenses and, as a consequence, large amount of fuel is burned, which inevitably causes air pollution with toxic substances. Annually the enterprise emits from 500 to 1250 tons of nitrogen oxide (about $50 \%$ of all emissions of the enterprise) into the city atmosphere, which pollute the soil with nitrogen compounds in the form of acid precipitation [8]. The fuel combustion, required for melting glass, is known to produce nitrogen oxide in the form of nitrogen monoxide (NO). Further, as a result of chemical reactions occurring in the air, NO turns into nitrogen dioxide (NO2)-orange-brown gas with unpleasant smell, dangerous and toxic, which is significantly harmful for humans and the environment. As nitrogen oxides dissipate in the air in the distance from the emission source, dangerous nitrogen dioxide is dominating in the air. World Health Organization research shows that the increased nitrogen dioxide content in the air might cause the development of various nosologies (from respiratory and cardiovascular diseases to oncology) [12].

To assess the probable impact produced by air pollutants on environment, it is impossible to rely just on the data concerning their presence in the air, due to the strong dynamics of concentration changes associated with the air masses transfer, wind (wind rose) change and strength, temperature inversion, atmospheric pressure, precipitation amount etc. Anyway, air pollution causes soil pollution in the city and surrounding areas, as it depends on atmospheric precipitation, for example, nitrogen compounds and their accumulation in the soil cover. So soil pollution can become a kind of an environmental pollution rate marker, despite contaminants absorption intensity by plants. The increased nitrates content in urban soil, compared to the control level, allows speaking of air pollution and health risks to the city population. 
Table 3. In Gorokhovets soil, $\mathrm{mg} / \mathrm{kg}$

\begin{tabular}{|c|c|c|c|c|c|c|c|}
\hline $\begin{array}{c}\text { Soik } \\
\text { sampling } \\
\text { points }\end{array}$ & $\mathrm{Sr}$ & $\mathrm{Pb}$ & $\mathrm{As}$ & $\mathrm{Zn}$ & $\mathrm{Cu}$ & $\mathrm{Co}$ & $\mathrm{Cr}$ \\
\hline 1 & $164,9 \pm 4,4$ & $64,5 \pm 2,8$ & $6,9 \pm 0,2$ & $81,3 \pm 22,9$ & $162,4 \pm 16,4$ & $40,5 \pm 11,3$ & $165 \pm 63,8$ \\
\hline 2 & $124,1 \pm 2,2$ & $60,6 \pm 3,4$ & $7,4 \pm 2,2$ & $57,4 \pm 6,4$ & $58 \pm 4,9$ & $5,8 \pm 2,7$ & $65,1 \pm 9,6$ \\
\hline 3 & $135,8 \pm 3,6$ & $62,9 \pm 9$ & $4,2 \pm 1,8$ & $56,7 \pm 5,3$ & $82,7 \pm 2,6$ & $9,2 \pm 0,6$ & $71,8 \pm 5,9$ \\
\hline 4 & $135,5 \pm 4,9$ & $65,7 \pm 9,9$ & $6,8 \pm 3,3$ & $52 \pm 3,8$ & $74 \pm 6,6$ & $7,3 \pm 1,1$ & $62,7 \pm 5,5$ \\
\hline 5 & $116,7 \pm 0,8$ & $57,7 \pm 3,5$ & $5,5 \pm 1,3$ & $43,2 \pm 3,7$ & $52,5 \pm 6$ & $3,65 \pm 0,4$ & $61,8 \pm 1,9$ \\
\hline 6 & $121,7 \pm 2,9$ & $92,1 \pm 7,7$ & $9,7 \pm 1,8$ & $84,3 \pm 2,5$ & $98,4 \pm 3,5$ & $15 \pm 3,2$ & $77 \pm 11,3$ \\
\hline 7 & $155,1 \pm 3,2$ & $68,6 \pm 7,5$ & $2,8 \pm 1,8$ & $106,7 \pm 2,6$ & $102,7 \pm 3,5$ & $17,3 \pm 3,3$ & $82,6 \pm 10,9$ \\
\hline 8 & $130,4 \pm 2,7$ & $103,1 \pm 6,8$ & $10,1 \pm 1,6$ & $73,3 \pm 2,2$ & $65,9 \pm 2,9$ & $4,5 \pm 2,6$ & $47,6 \pm 8,9$ \\
\hline 9 & $132,7 \pm 2,9$ & $116,8 \pm 7,6$ & $9,1 \pm 1,8$ & $157,4 \pm 2,9$ & $96,3 \pm 3,4$ & $13,1 \pm 3,3$ & $120,9 \pm 11,3$ \\
\hline 10 & $141,5 \pm 2,8$ & $61 \pm 6,8$ & $5,9 \pm 1,6$ & $80,1 \pm 2,3$ & $92,4 \pm 3,2$ & $13,9 \pm 3,2$ & $109,3 \pm 10,5$ \\
\hline 11 & $214,1 \pm 21,9$ & $78,8 \pm 10,5$ & $8,7 \pm 1,3$ & $153,6 \pm 28,1$ & $74,6 \pm 10,3$ & $7,7 \pm 3,7$ & $69,4 \pm 7,1$ \\
\hline 12 & $121,9 \pm 6,8$ & $67,7 \pm 0,3$ & $10,9 \pm 2,4$ & $174,8 \pm 26,4$ & $81 \pm 11,7$ & $17,9 \pm 9,9$ & $113,2 \pm 5,1$ \\
\hline
\end{tabular}

The anionic composition analysis of water extracts from soil in Gorokhovets revealed sulfate ions excess (sampling points No. 3,4,9) connected with the emissions of sulfurous anhydride into the air from glass packaging plant "Ruscam". It was stated that sampling points varied widely in nitrate concentration: from $2.8 \mathrm{mg} / 1$ up to $9.8 \mathrm{mg} / 1$. The greatest increase, in comparison with the control level, was observed for nitrate ions, and the highest levels of nitrate were found in the central area in Lenin street (points 6,8,12) and in the area around Glass packaging plant "Ruscam" (point 4).

Thus, the increased content of sulfate and nitrate ions in the soil of these areas, compared with the control level, indicates anthropogenic air pollution with sulfur and nitrogen compounds, which might be dangerous for the population health. It should be focused that the soil composition and properties differed at different points and it affected nitrates content in soil. Mobile mineral forms of nitrogen in soil are known to depend on a number of factors: soil acidity and physico-mechanical properties, soil-forming rock composition, hydrological and weather conditions, microbiological processes, and especially in urban soils - the degree of soil compaction, soil contamination with extraneous inclusions, the level of anthropogenic load, etc. Nevertheless, it is reliably determined that at all sampling points nitrate content is higher than in the control sample, regardless of soil composition and properties. It indicates of the complicated problem for the city pollution with nitrogen compounds.

Besides it is worth mentioning that soil in the city and around the plant "Ruscam" was sampled in summer, and in summer minimum nitrogen oxides concentration is detected in the air, in comparison with the winter period, when beside of all above mentioned emission sources of nitrogen compounds, heat power engineering complex is added during the heating period in the city. Thus, in winter nitrogen oxides load on the population is harder and may exceed sanitary and hygienic standards in some city areas. Such load can become critical and lead to a possible surge in various types of morbidity among different population groups for the town of Gorokhovets, characterized by small area and population.

\section{Conclusion}

The ecologic-hygienic assessment of the environment has revealed that vehicles have made the largest contribution to the air pollution in Gorohovets in recent years. The main stationary source of air basin pollution is the plant "Ruscam", which emits nitrogen oxides, 
formed in the process of glass packaging production. The revealed increased rate of soil nitrate pollution in the town, in comparison with the control levels, might testify of the possible development of various pathological processes among the town population.

\section{References}

1. L.V. Veremchuk, Influence of air pollution on the formation of levels of the general incidence of bronchopulmonary pathology in Vladivostok, 55(1), 4-8 (2014)

2. T.A. Trifonova, A.A. Martsev, Assessment of the impact of air pollution on the incidence of the population of the Vladimir region, 94(4), 14-18 (2015)

3. L.I. Sverlova, The scientific basis of the modern approach to assessing the level of urban air pollution, 7, 22-25 (2009)

4. M.V. Yarygina, P.F. Kiku, Features of population morbidity in modern socioecological conditions of the Primorsky Territory, 2, 100-103 (2014)

5. D. Tang [et al.] Health benefits of improving air quality in Taiyuan, China. Environ Int, 25(73): 235-242 (2014)

6. V.A. Shashel', Influence of the polluted environment on the formation of erosive and ulcerative processes in the stomach and duodenum in children in conditions of the Krasnodar Territory, 4, 62-65 (2009)

7. T.A. Trifonova, A.A. Podolec, O.G. Selivanov, A.A. Martsev, A.A, Podolec, Assessment of soil pollution of recreational areas of an industrial city by compounds of heavy metals and arsenic, 2, 94-101. (2018)

8. N.A. Ishun'kina, Improving the environmental sustainability of glass production: the example of the Vladimir region (2008)

9. Yu.E. Saet, B.A. Revich, E.P. Yanin, Environmental Geochemistry (1990)

10. http://gorohovec.ru/

11. A.G. Ageev, YA.N. SHojhet, A.F. Lazarev, The influence of environmental factors on the incidence of lung cancer in the Altai Territory, 2, 13-14 (2009)

12. P.Yu. Silaeva, A.V. Silaev, Peculiarities of dispersion of emissions of nitrogen dioxide by enterprises of the energy complex and their impact on the population of cities, 26 (1), 63-72 (2018) 